\title{
The Modern Interior and the Excitation Response: Richard Neutra's Ocular-centric Phenomenology
}

\author{
Michael J Ostwald*, Raeana Henderson
}

School of Architecture and Built Environment, The University of Newcastle, NSW, 2308, Australia

\begin{abstract}
While typically characterised as a canonical Modernist, Richard Neutra's design theory repeatedly refers to the central role played in his architecture by the works of experimental psychologist Wilhelm Wundt. In the late Nineteenth Century Wundt used laboratory experiments to demonstrate that human responses to sensory stimuli were both immediate and predictable. Despite Wundt's importance in many fields, architectural scholars have tended to disregard Neutra's fascination with Wundt's complex physiological and biological theories. However, this paper revisits Neutra's design theory, accepting, prima facie, his belief in the causal relationship between physiology and psychology to suggest an alternative reading of his architecture. By tracing the influence of Wundt's ideas on Neutra's design theory, the paper identifies a singular ocular-centric, phenomenological tendency in the resultant architecture. The implications of this approach are then considered in the context of three facets of Neutra's domestic architecture in general and the Kaufmann Desert House in particular. Computer models and diagrammatic analysis are used to support this reading of Wundt's influence on Neutra's design.
\end{abstract}

Keywords Richard Neutra, Phenomenological Analysis, Interiority, Modernism

\section{Introduction}

Despite his reputation for producing stark, white, geometric designs, which otherwise appear to conform to early Twentieth Century Modernist ideals, Richard Joseph Neutra repeatedly described his architecture as serving to choreograph the sensory and emotional responses of the human body[1-3]. Long before architects became interested in the philosophy of phenomenology, Neutra called on the theories of pioneering psychologist Wilhelm Maximilian Wundt, to argue that the most important purpose of design was to control the senses to clarify the body's position in space. Superficially at least, this view has much in common with those of Christian Norberg-Schulz[4] and Juhani Pallasmaa[5]; amongst the key proponents of architectural phenomenology in the late Twentieth Century. However, these authors have been highly critical of both Modernism and of the privileging of vision that accompanied the rise of functionalist thinking in architecture[6]. The origins of this division, between the theories of Neutra and those of the architectural phenomenologists, can be traced to the conflicting views of their predecessors; respectively Wilhelm Wundt and the philosopher Edmund Husserl.

While Husserl was a student at Leipzig University in 1879

* Corresponding author:

Michael.Ostwald@newcastle.edu.au (Michael J Ostwald)

Published online at http://journal.sapub.org/arch

Copyright $(\underset{2}{ } 2012$ Scientific \& Academic Publishing. All Rights Reserved he attended the lectures of Wundt, who was at that time formulating a way of isolating and measuring bodily responses to external stimuli (like heat or sound). Whereas, over the following two decades the scientific world grew to embrace Wundt's vision, Husserl rejected this paradigm and began to formulate a counter-position that relied on the primacy and irreducibility of human experience. Husserl's philosophy of phenomenology argued that human knowledge and awareness is necessarily reliant on the experience of the world through all of the senses[7]. Husserl's student Martin Heidegger developed this theory to support an inquiry into the nature of being and existence[8]. However, in the hands of architectural scholars, the spiritual dimension of Heidegger's philosophy was translated into an argument for the existence of a transcendent quality in certain buildings or places. While it no longer bears a strong connection to its philosophical antecedents, in contemporary use architectural phenomenology is typically presented as a search for authenticity or truth, through the production of architecture that evokes a deep, sensory appreciation of place, space or tectonics. A position which has several elements in common with Neutra's call for architecture to strategically use space and form to shape each individual's sensory response to their place in the world.

The division between contemporary architectural phenomenology and Neutra's theory of sensory choreography (called "biorealism") is essentially one between, respectively, poetry and science. This is not to say that Neutra's ideas lack poetry nor that Norberg-Schulz's, for example, have no 
recourse to science. But rather, that Neutra's ideas privilege a particular scientific or clinical foundation for his design theory while those of the architectural phenomenologists tend to valorise the poetic and the metaphysical. In much the same way that both Wundt and Husserl were fascinated with the role played by the human senses in understanding the world, but resorted to different ways of achieving their ontological goals, so too Neutra, despite obvious differences with Norberg-Schulz and Pallasmaa, cannot be so easily detached from the phenomenological tradition.

This paradox, as several scholars have noted, begins to explain why Neutra occupies such a contradictory place in Twentieth Century architecture[9-10]. He was a designer whose work appeared to be defiantly modern but who was more interested in the way the human body reacts to space and form. Moreover, Neutra's theories were rarely easily accessible, with Kruft describing Neutra's books as "repetitive", "unsystematic" and "hard to read"[11 p432]. The lack of clear connection between his ideas and his buildings served to exacerbate this problem, leading to a proliferation of interpretations of his architecture with little regard for the theory underlying them[12-13]. It is through such scholarship that Neutra's architecture has been repeatedly categorised as a type of socially informed, technologically enabled, response to the zeitgeist. However, more recently researchers have begun to take Neutra's theory more seriously and in doing so have identified aspects of anthropology and Freudian psychoanalysis that are deeply significant[14-15]. Furthermore, Neutra's dislike of elevations - he typically presented perspective views and plans to clients - has triggered renewed consideration of the visual qualities of his architecture[9],[16]. In all of these recent cases there has been an attempt to reconcile Neutra's complex psychological and physiological theories with his architecture.

The present paper, which is an extension of this recent research, proposes a reading of Neutra's theory and architecture that is premised on reinstating the significance of Wundt's ideas. This research is not concerned with whether Neutra's (or Wundt's) claims about the human body and sensory perception are accurate, but only that they have been used to make a particular case about the relationship between the body and the environment. By using Wundt's theories as a catalyst, it is possible to focus the research on a set of narrow but repeated assertions in Neutra's writings about architecture. Through this new analysis, the centrality of the eye in Neutra's theory is affirmed, not only as enabler of sight but also as a predictable physiological system. By focussing on the importance of the eye in shaping bodily responses to space and form, the immediacy of the interior experience in Neutra's domestic works is stressed. Viewed in this way, it is possible to interpret Neutra's domestic interiors as a type of a laboratory apparatus, attuned to controlling excitation response.

This paper commences with a review of a critical passage from Wundt's work, which Neutra was later to repeatedly paraphrase as an explanation for his design decisions. In this section two important themes are identified. First, the role of the eye, as the primary sensory apparatus, which Neutra believed shaped the actions of the body. Second, the time taken for the body to react to external stimuli. Thereafter, Neutra's imagined narrative of the body's involuntary excitation in response to the visual properties of one of his designs is analysed, finding similar themes to those identified in the previous review of Wundt's influence. In the penultimate part of the paper three examples of Neutra's possible adaptation of design to reflect his extrapolation of Wundt's theories are traced in his domestic works, before particular examples from the Kaufmann Desert House are described. These three examples include a planning strategy, a formal approach and detailing practice. The interpretation offered by this section of the paper is supported by several computer-generated images, isovist views and diagrams that broadly reflect Neutra's arguments about the eye and movement. Because the primary purpose of these computer images is to illustrate the text of this paper, the full detail of their generation is not provided, but references are given for the techniques that have been used. Thus, these images and figures support a particular interpretation rather than providing a universal proof. Just, as the evidence for architectural phenomenology has been criticised for being self-referential and arbitrary[17], so too this reading of Neutra's theory of how people will react in space is similarly conjectural. However, the purpose of this paper is not to justify a design theory or approach, or to debate the merits of phenomenology. If Neutra's claims about the way the body will react in space are taken as argumentum a fortiori, then this approach is a reasonable way to posit a reading of one of his buildings.

\section{Ocular-Centric Phenomenology}

Early Twentieth Century physiologists described the involuntary muscular contraction that occurs in reaction to external stimulus as a reflex action or excitation response[18]. An example of a reflex action is when a crossed leg is lightly struck on the knee, the leg will respond with an immediate tremor. This is because the quadriceps muscle in the top of the thigh contracts in response to the pressure, triggering the lower leg to move. A similar, but more complex reaction was thought to occur when the eye reacts to something it sees. As Wundt explains, we can readily understand that reactions to light impressions can be released in the mesencephalon, without any participation of the principal path; released as reflexes to the oculomotor system, by way of the transferences effected in the quadrigemina, and as reflexes to other muscles of the body, by way of the other connexions.[19 p90]

In this instance, Wundt theorised that the responsive cells at the base of the eye (quadrigemina) send a message to the midbrain (mesencephalon), which in turn signals the muscles surrounding the eye, and at the base of the eyelid (the oculomotor nerves) to control the way the head is facing. Such a reaction to visual stimuli was not only thought to be 
immediate, it was also assumed to be pervasive; that is, all people with normal neurone and muscle connections would react in a similar way. When Neutra began his architectural studies in 1911 at Vienna's Technical University, he discovered a copy of Wundt's famous Principles of Physiological Psychology wherein this passage about the eye, body and human experience is contained. Sylvia Lavin describes this text as a most influential work, "to which Neutra refers countless times"[20 p35] in his design theory. Barbara Lamprecht[9] similarly observes that Neutra was repeatedly drawn to Wundt's text and Neutra attributed his abiding interest in "biological and behavioral heritage" to "the writings of[this] influential German physiologist"' $21 \mathrm{p} 30]$.

However, despite all of Neutra's references to Wundt, architectural scholars have tended to ignore this connection. Alternatively, if they have broached the topic of Neutra's singular view of phenomenology, they have interpreted it from a Freudian psychoanalytical perspective. But, as Thomas Hines notes, in his youth Neutra rejected Freud's theories drawing instead "on the more scientifically based revelations of Wilhelm Wundt"[10 p12]. According to Lavin, to a young Neutra "Wundt's discussions of nerve endings, ganglia, modulations of the retina, and sensory receptors[...] was both progressively precise and reassuringly familiar" $[20$ p35]. It is through Wundt's work that Neutra "sought to identify the myriad steps involved in transferring a physical object in the world along the chain of perception until it became first a sensation registered in the brain and then a feeling”[20 p35].

In a view that parallels Wundt's theories[19][22], in his seminal 1956 book Life and Human Habitat, Neutra argues that,

various and intimate are the nerve connections between the emotional tract of the thalamus, the middle brain, and those highly developed associations of the cerebral cortex, the sensory reactions, the muscle activations, and the secretion of internal glands, all of which in integration have deep meaning to our life and determine psychosomatic rhythm, tempo, and intensity.[23 p22]

From this conceptual foundation, Neutra developed the proposition that the human body is a responsive system and that certain sensory experiences will elicit immediate and predictable excitation reactions. Neutra goes on to argue, like Wundt before him, that the human eye's "influence on consciousness seems stronger than that of all our other sense receptors"[24 p138]. Furthermore, Neutra stresses this position when he proposes that "the human eye is much more developed and more sharply focused than the ear'[24 p138] because it is "equipped to be stimulated not only by light and colour but by form and movement as well'[24 p181]. While Neutra does not ignore the other senses - describing both the olfactory and auditory in some detail -he repeatedly privileges the eye in his writing. In order to translate this way of viewing the human body and its senses into a theory which could support design, Neutra highlighted two qualities of the psycho-physiology of the eye. The first of these is associated with the belief that the eye can trigger involuntary responses in the body and the second is about the time taken for this reaction to occur.

One of Wundt's most seductive propositions was that "the reflex to the muscles that move the eye-ball is connected[...] with contraction of the corresponding muscles for movement of the head"'[19 p294]. By inference, Neutra argues that this means that vision is a necessary precursor to movement. While, on a quotidian level, this is almost always true, Neutra actually means that if the eye is involuntarily drawn to see something, this will trigger the head to turn towards that visual stimuli, which will in turn change the direction the entire body is moving in. Thus Neutra's famous maxim is; "we 'see not merely to see' but see in order to act upon vision"' 23 p13]. Or alternatively, vision "will activate a person's locomotor urges"[23 p14]. In these claims, Neutra makes the first step towards conflating the eye and the body, a tactic that was to later become a standard part of his design rhetoric. Because the eye both guides the body and activates the most powerful of its responsive urges, Neutra often distilled the body and its actions into the responses of the ocular nerves and associated muscles. In essence, the human body was interpreted as a mass of responsive tissue in the service of the eye.

The second facet of Neutra's design theory about the eye involves time; a factor which plays a paradoxical role in the work of both Wundt and Neutra. With the assistance of new laboratory apparatus in the late Nineteenth Century it had become possible to measure smaller units of time that had previously been dismissed as effectively instantaneous. However, despite these advances, the technology was still not able to measure response rates with any accuracy[25-26]. This situation was problematic because Wundt understood that all sensation was transmitted through a sequence of muscles and nerves before a reaction could occur. He reasoned that this response could not occur without some passage of time, but in practice the time interval between stimulus and response was so small as to defy measurement. The solution was to imagine the reactions as occurring in the present. This was effectively a compromise between observed and measured behaviour or a way of reconciling the relationship between the theorised understanding of the nervous system and the apparent immediacy of the reflex response. Neutra's development of this idea is similarly fraught with compromise. For example, Neutra understood that that body's response to vision is "by no means instantaneous"[24 p181]. However, in practice, Neutra described muscular responses as occurring in parallel with the moment of stimulation. In order to accommodate this blurring of time, Neutra began to imagine the body experiencing and reacting to stimuli in a sequence which was continuously occurring. Thus, the body was thought of as not only reacting in the present, but also as existing in a perpetual present state. That, in hindsight, the body always exists in a perpetual present state is not important[25]. What is more interesting is the way in which these concepts - the role of the eye as surrogate 
body and as agent of the present - were to find a role in both Neutra's design theory and in his architecture.

Neutra identifies four types of ocular-centric reflex responses; a base state, a "defence reflex" and two excitation responses, "startle" and "orientation" (figure 1). Each of these behavioural patterns is a result of visual-spatial stimuli that cause involuntary reactions in the body's nervous system. This belief is not only founded on Wundt's ideas, but on anthropological research which argued that human physiology is a result of evolutionary processes derived from primitive human survival instincts. Thus, the "fittest" of the human species are those who have developed a type of constant sensory awareness of their surroundings that is conducive to survival[2-3]. It is this concept that Neutra ultimately adopts to justify a transparent architecture; one with appropriate prospect or surveillance potential. However, before examining the connection to architecture in detail, the four types of reflex situation, which make up the core of Neutra's evolutionary thought, are further considered.

In any interior, a primary or first-order, directional reflex governs the normative position of the body, the head and the eyes in a space. This reflex could be thought of as equating to the longest internal vista in a space; the primary vector intuitively selected by the body for maximising orientation. However, various forms of visual stimuli will cause the eyes (then the head and the body) to depart from this line and look or move in a different direction. A secondary or second-order, involuntary defence reflex is the force that causes this change in direction to occur. This reflex is innately associated with peripheral vision; a physiological system which has the capacity to put the body's nervous system at ease or to alert it to danger. According to Neutra, the defence reflex exists "for the purpose of alarm in the vision field, so that we can turn quickly to any point within this visual realm wherever something suspicious in movement or colour or brightness might occur"[23 p13]. Moreover, peripheral vision affects eye movement leading Neutra to state, "it almost continuously causes us to reset and turn the eyes in quick, small movements whenever we take in a wide interior or broad exterior" [23 p13].

In contrast, the orientation reflex is a third-order of response which is concerned with the way in which the eyes are drawn towards external stimuli for the purpose of locating the body in relation to the source of the new stimulus. Thus, Neutra explains, auditory stimulation (sound originating from the side or back of the head) triggers the face to move, because it "has its eyes, its visual receptors, lodged in the front of the head"[24 p161]. This orientation reflex occurs because "the receptor areas are turned for best exposure to the stimulus or in the direction of its impact"[24 p219]. Neutra also associates the brightness or contrast of light to the orientation reflex, which he identifies as a Pavlovian response, arguing that "a noise, a flash of light, makes a dog and us as well sit up."[24 p219]. Neutra's final type of response, the startle reflex, is also a third-order reaction which is a more instantaneous and dramatic version of the orientation response. If Neutra's descriptions of the three orders of reflex response are accepted as a primary mechanism shaping his approach to design, then it should be possible to find evidence for their use in his architecture.

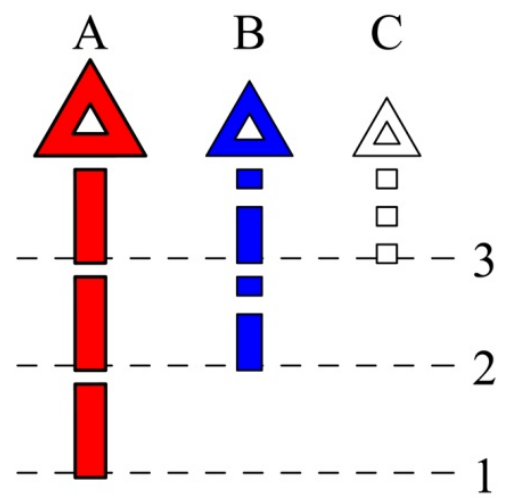

Figure 1. Diagrammatic and hierarchical representation of the types of reflex response mapped to the Kaufmann Desert House examples in this paper. (A) directional; (B) defence; (C) orientation and startle

\section{Designing Reflexive Architecture}

In Life and Human Habitat, Neutra outlines the principles of biorealism; a theory which he had primarily developed through his residential designs. In this work he identifies the home as the single place on "the surface of the globe which we get to know intimately" $23 \mathrm{p} 21]$. Neutra believed that the constructed environment is "full of [...] visual collision, of turmoil to the eye, and of neglected optical litter" and that it is the most intimate spaces of the home which are often the cause of "visual conflict"[23 p166]. In response to this situation he set out to produce designs that could shape the combined physical and psychological responses of the body. In practice, this meant that he not only presented his designs as perspective drawings, an approach which accentuates the centrality of the eye, but he also provided a parallel, imagined account of the experience of the design. These accounts typically focussed on the visual connections between the body and form. For example, when describing the experience of a house, he provided the following imagined account.

As we approach we raise our head to recognize the house number, and in the motion we possibly glance over the roof, its configuration and skyline. As we tilt our head upward, the equilibrium or inner ear organ immediately functions and combines the manifold record of our body position with pure vision and its ever-changing perspectives. We roll our eyes by means of that ingenious muscle cluster around our eyeballs which is intricately and neurally tied up with those tools which we use unconsciously for turning and tilting the head.[...] Now, with our hand touching the knob of the entrance door, tactile and thermal experience of conductive and polished metal comes to us through the fingers and palms of the hands, while at the same time the muscle senses faithfully report from below about the rubber mat on which we have stepped.[23 p13]

In this account Neutra immediately connects sight with physical response; "we raise our head to recognize the house 
number." Furthermore, by referring to a house number, Neutra infers the presence of a suburban street and, as the viewer's gaze rises over the roof, they observe nature, which possibly suggests an affluent neighbourhood. All of this information constructs a picture, through the visitor's imagined sensory response, of a desirable setting. Notably, Neutra's description is constructed from a collective, universal perspective; magnified through the use of the first-person, collective pronoun "we" throughout.

Of similar importance in Neutra's narrative is the use of present tense to describe physical reactions as they occur. This is not only a literary conceit, but it reinforces the idea that universal anatomical reactions are constantly occurring in parallel to the visual experience of environmental conditions. Thus, Neutra identifies that the muscles around the eye are connected to muscles of the head; recognising that both eye movement and head movement are inseparable. Because Neutra argues that vision precedes any movement of the body, then external visual stimulus must first prompt the combined reactions of both the muscles of the eye and of the head. Hence, in his description of the approach to the house, sight always precedes reaction, although the response is effectively instantaneous, occurring in a perpetual present state. Thus he describes how, "we raise our head" and "glance over the roof."

The presence of gravity and the depiction of perspective in the account confirms the eye's complicity in the loss of the body. First, the "eyes[...] discern the ceiling, walls, and window frames in perspective related to the horizon" $[23$ p18]. The presence of the horizon affirms the role of the body both resisting gravity and as armature of the senses. Neutra theorised that "gravitational sensibility[...] deeply affects our appreciation of[an] architectural environment"[24 p53)]. The body's internal responses to gravity also combine with the "visual impressions" recorded by the eye, creating "oblique perspectives" through which the design is experienced[24].

On the pages of his seminal books, these imagined accounts were presented alongside photographs, plans and perspective drawings of Neutra's houses suggesting graphically that the designs somehow illustrated the accounts. Nevertheless, meaningful connections between the text and the designs are rare, with most operating at a very general level. For example, if the text stressed the importance of the landscape, a photograph might be presented of a building against a natural backdrop. Similarly, if the text described the role played by an entry in framing the experience of the living room, the accompanying image would be of the door to the living room. Without further annotation or description the connections implied by this juxtaposition of images and words remains abstract. However, there are three partial exceptions to this rule, associated with a specific planning strategy, a form-making approach and a curious detailing practice. Each of these three are considered hereafter, first as applied in various different buildings, before their presence is traced in one of Neutra's most famous works, the Kauf- mann Desert House (figures 2, 3 and 4).

\subsection{Pinwheel Plan}

Neutra was an advocate of the "pinwheel" floor plan, a cruciform spatial arrangement which is found in many of his houses[9-10][27]. In such plans, each quadrant typically has a circulation edge with a solid wall to one side and a glass or open wall on the opposite side. Thus, each quadrant has a dominant visual orientation that is controlled by the location of screens or walls. This planning strategy is evident in the Moore and Kramer houses where specific "transparent walls open upon a panoramic view of mountains and valleys" $[12$ p18]. Neutra argues that such planning directly responds to human visual needs, claiming, "the architect would have no chance to impress human beings in space if there were no peripheral vision"[23 p13].

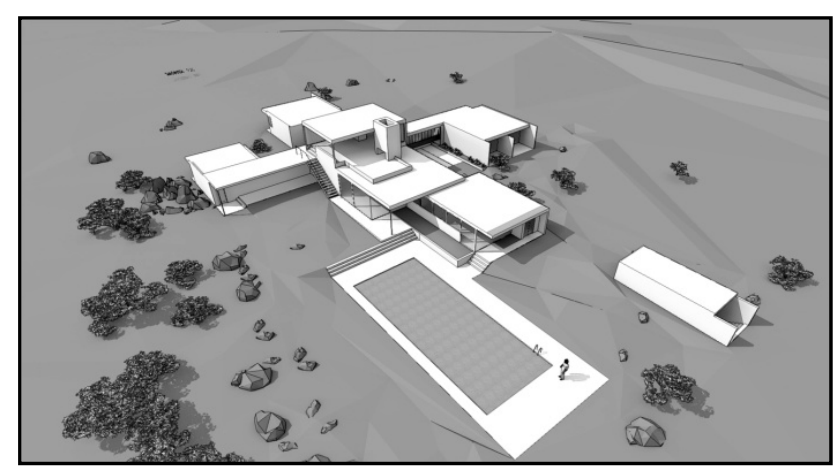

Figure 2. Kaufmann Desert House, Palm Springs (1946), Richard Neutra

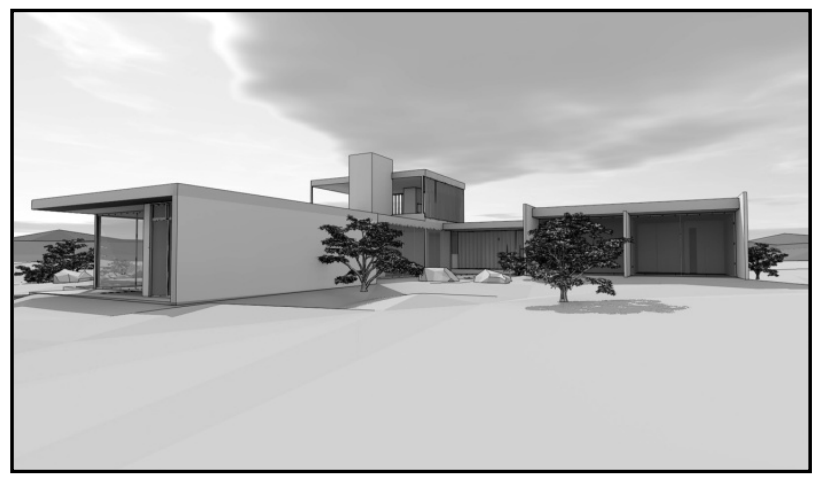

Figure 3. Kaufmann Desert House, Perspective view

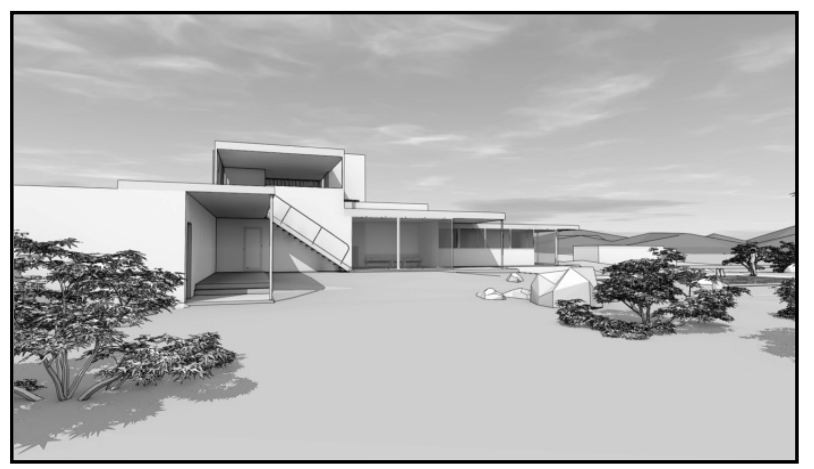

Figure 4. Kaufmann Desert House, Perspective view 

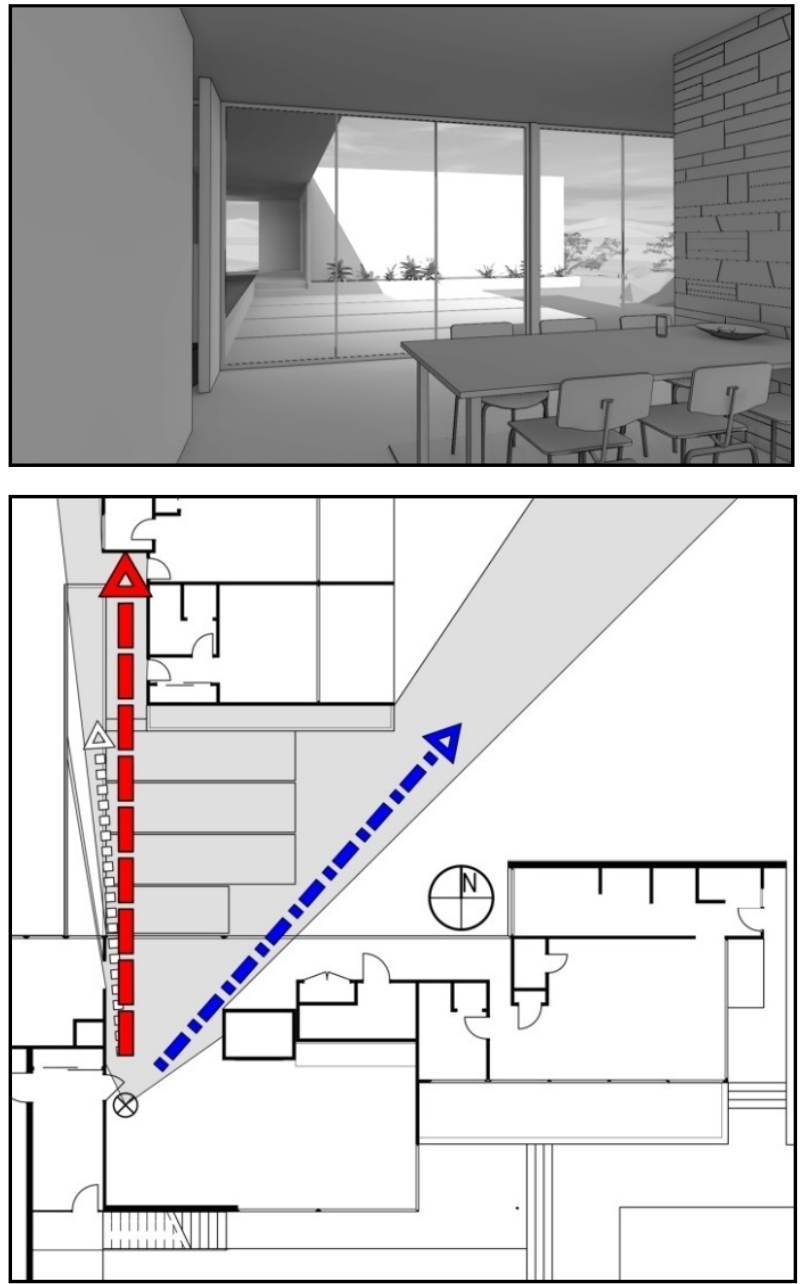

Figure 5. Parallel perspective (upper) and isovist (lower) views of the Kaufmann Desert House, annotated to identify predicted reflex response

The Kaufmann Desert House is not only one of Neutra's most well known works, but it has also previously been the subject of a comprehensive visual and geometric mapping analysis which informs the present reading[28-29]. In this house, the entry doorway provides one of the strongest directional reflexes; a path initially defined by a long garage wall which then steps into the plan, before continuing through the dining area and by way of a semi-enclosed courtyard to the guest wing. While traversing the early stage of this route, the visitor is enclosed within a stone-lined corridor, but thereafter a clear visual path leads across the dining area, parallel with a long stone wall, and towards a small, vertical orientation reflex view, to the left of the original directional path (figure 5). However, soon after passing only the direction path, and a peripheral orientation view to the south-east, a major vista, elicited by the second-order defence reflex, between the arms of the pinwheel plan draws the body to look towards the distant mountains in the north-east. The courtyard surface is paved in a stepped pattern to accommodate the body's involuntary passage towards this vista. Walls or banks of louvres tightly control all other views along this original path including framing (figure 6).
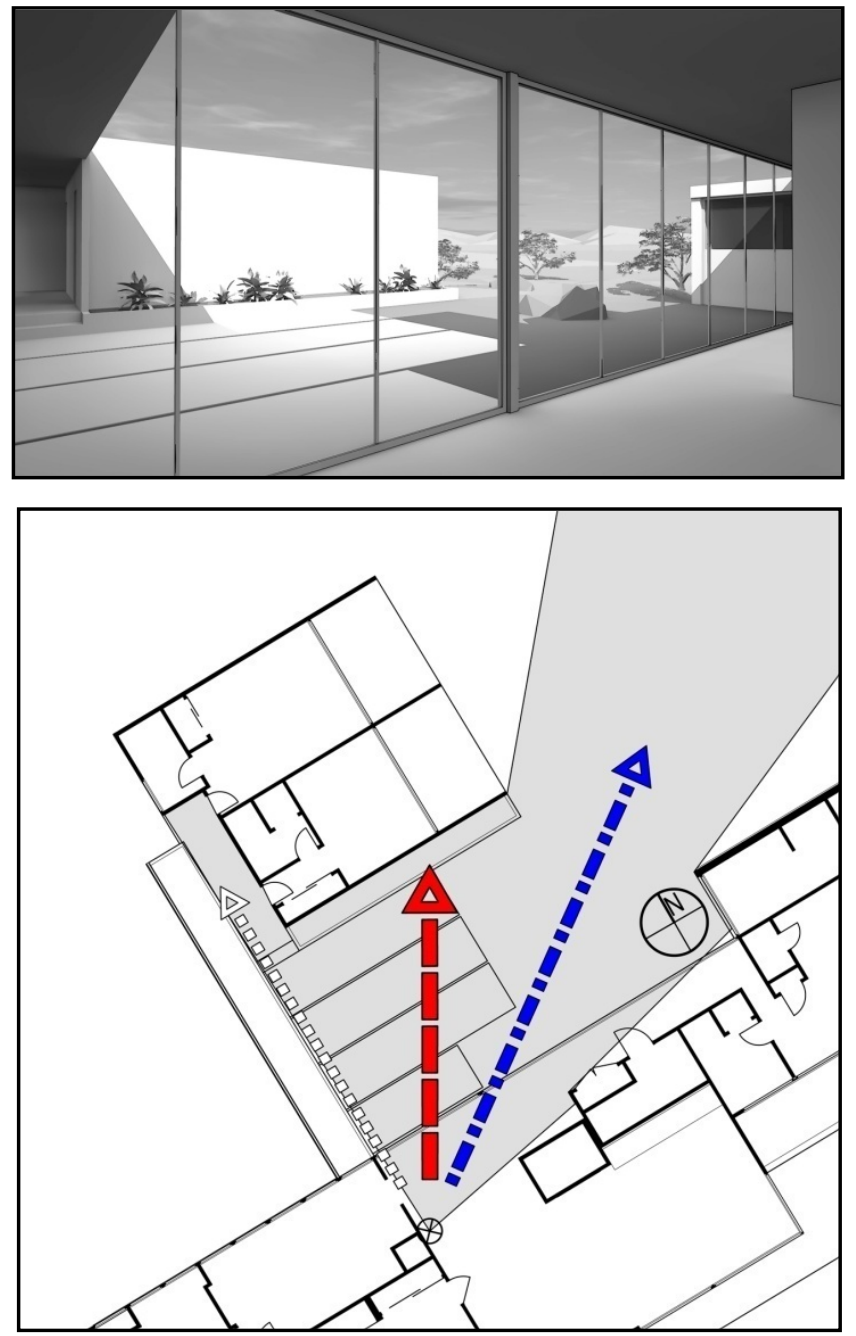

Figure 6. Parallel perspective (upper) and isovist (lower) views of the Kaufmann Desert House, annotated to identify predicted reflex response

The single longest visual path through the interior of the Kaufmann Desert House connects the servant's wing, through the entry foyer and living room, out to the pool terrace[29]. This directional reflex path crosses the previous one in the doorway between the entry and the open plan living area. The key moment in this house occurs at this intersection, not coincidentally the site of several famous photographs of the interior $[9,16]$. While the primary directional reflex draws the visitor through the living room, and along the edge of the terrace, a series of substantial second order reflexes pull the eye, and the body, towards the pool and the landscape beyond. The pool itself, like the courtyard paving in the previous example, steps out from the cruciform walls at the heart of the plan, drawing the eye and accommodating the body's movement along the new path[29].

Neutra argues that it is possible to choreograph human experience, using space and form to cause the eye "to jump to the perception of accentuated points or features in the design, and thus the eye, the head, even the whole body will turn readily towards such attraction" $23 \mathrm{p} 13]$. This is the case in the two examples of vision and movement in the Kaufmann Desert House. 


\subsection{Planar Juxtaposition}
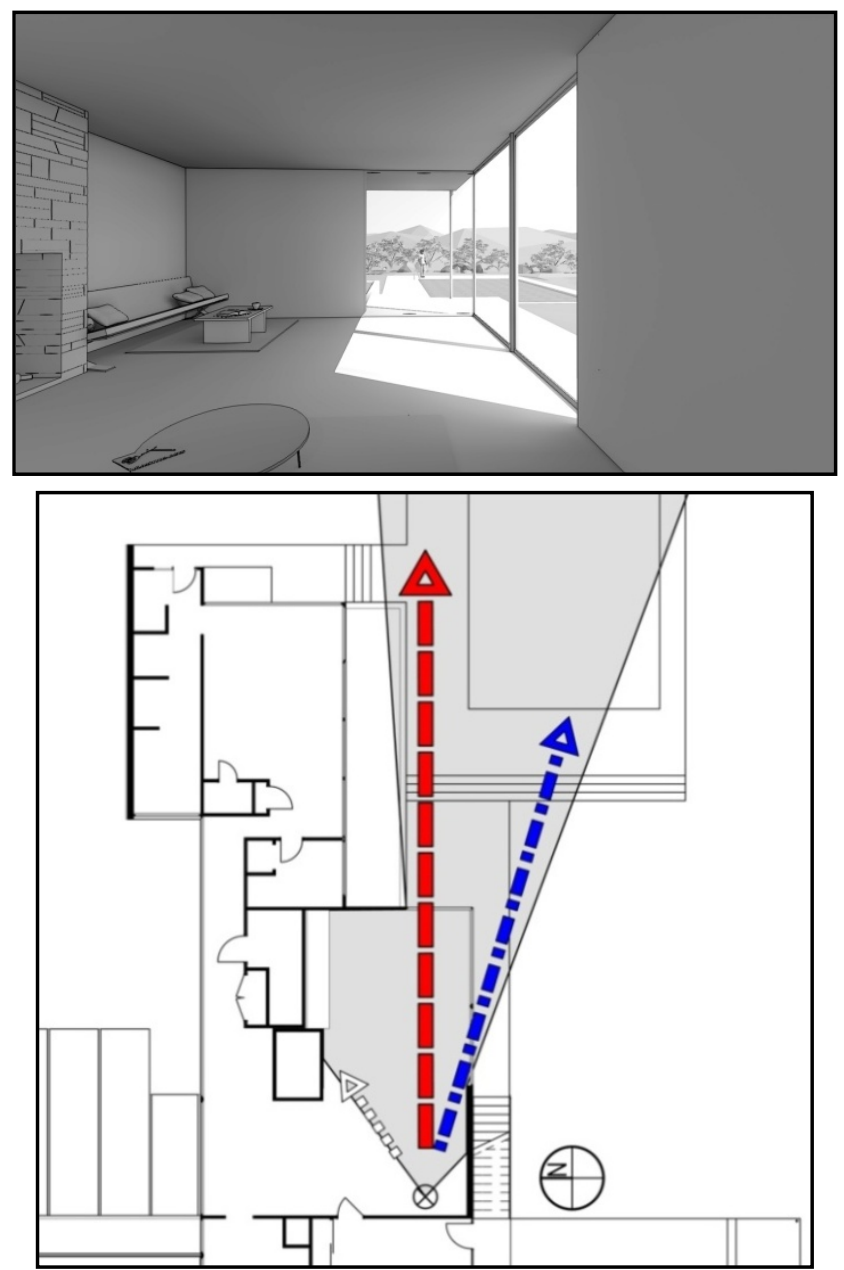

Figure 7. Parallel perspective (upper) and isovist (lower) views of the Kaufmann Desert House, annotated to identify predicted reflex response

Neutra's use of the flat, horizontal planes in his houses is another common formal strategy. This approach is typically used in combination with pinwheel planning strategies to control the vertical extent of a person's cone of vision. For Neutra, these horizontal planes situated over transparent walls "allow a wider scope for peripheral vision" [9 p48] which controls the defence and orientation reflex responses, thereby connecting vision and movement. An example of this is found in Neutra's Bailey House (1946) which features a horizontal roof and floor to ceiling glass walls. This combination of forms lead the client to observe that the design "does not just sit here passively" rather it "acts on[him] in a most beneficial manner"[qtd in $10 \mathrm{p} 235]$. Attracting attention from visitors, Bailey also records that the house caused physical responses from such people who were always "adjusting their gazes" within the home. Bailey even wondered whether, as Neutra proposed, the visitors felt the same way about the home as Bailey did, asking "is it that the building acts on them too[and] tells them some archetypal truth which sets them free?"[10 p235].

McCoy describes the Kaufmann House as a structure dominated by "horizontal planes[which] hover over trans- parent walls"[12 p16]. This approach is especially evident in the corner of the living room adjacent to the pool terrace. As described in the previous section, in plan this space is notable for having a directional reflex parallel to the walls of the house, and a defence reflex angling the body to the south east of this line of sight, across the terrace itself. The horizontal roof over this area, which other than a single supporting column (described in the following section), is sited above the intersection of two glass walls. From the interior the roof is extended to the east, narrowing the cone of vision and directing the view through a large pane of glass accentuating the original directional impulse[12]. However, the roof does not extend beyond the line of the glass wall to the south, meaning that the primary directional reflex is tightly framed by the roof, while the defence reflex path is more sudden, twisting the viewer to the south, possibly causing Neutra's third-order, startle or orientation responses (figure 7).

\subsection{Dematerialising Columns}

Hines considers the idea that, because Neutra was "striving for industrial effects to suggest the possibilities of replicable mass production" he painted many surfaces in his designs silver; a practice which might be regarded as "'dishonest' $[\ldots]$ according to modernist moral canons" $[10 \mathrm{p} 131]$. However, if technology is of less importance than the body's response to visual stimulus, then Neutra's well-known practice of painting particular columns silver, might have another explanation. For example, some of Neutra's residential designs, including the Beard House (1935) and the von Sternberg House (1936), required protective coatings as they were entirely steel-framed and these may have been painted for practical reasons. However, when using stainless steel cladding, such as in the Brown House (1955), Neutra particularly chose to use silver "only in those places where the sightline is affected", a decision he claimed was specifically in order to "dematerialize" the structure[qtd in 9 p34]. Furthermore, in his later works, such as the Clark House (1957), the silver paint was applied in accordance with sightlines generated only from within the home "because it was the view out that mattered" $[9$ p34]. In both cases it is clear that the silver paint was not applied to artificially conform to modernist expectations but was motivated by the desire to shape the visual impact of the structure on the body's reflex system. Thus, in Survival Through Design Neutra maintains that in certain circumstances the visual dominance of columns could prevent the "natural gratification in feeling visually unimpeded and in being free for action, at liberty, not caged and incarcerated"'[24 p219].

In the previous two sections, on the pinwheel planning strategy and floating roof planes, a critical location in the Kaufmann Desert House was identified where the longest visual path across the plan, corresponding to the first-order directional reflex, is momentarily diverted, through the use of horizontal and vertical forms, by a second-order defence reflex, and thereafter by a third-order, startle or orientation reaction. This progressive transition from first, to second to 
third-order reactions in the body is reliant on the combination of uninterrupted glass walls, from the south and east sides of the living room, which meet in the corner of the space. These glass walls share a single joint, which is also the only structure supporting the overhanging roofline, a silver painted, steel and timber post (figure 8). This moment in the house is singled out by Lamprecht as the most important in the entire house because " $[t]$ o stand there is to be engaged in a physically charged moment" $[9 \mathrm{p} 179]$. This moment, which previous scholars have identified as being central to the experience and presentation of the house $[9-10,12,16]$, is a rare instance in Neutra's architecture when his phenomenological agenda may be traced, by way of his imaged choreography of human visual experience, in the design and detailing of a single project.
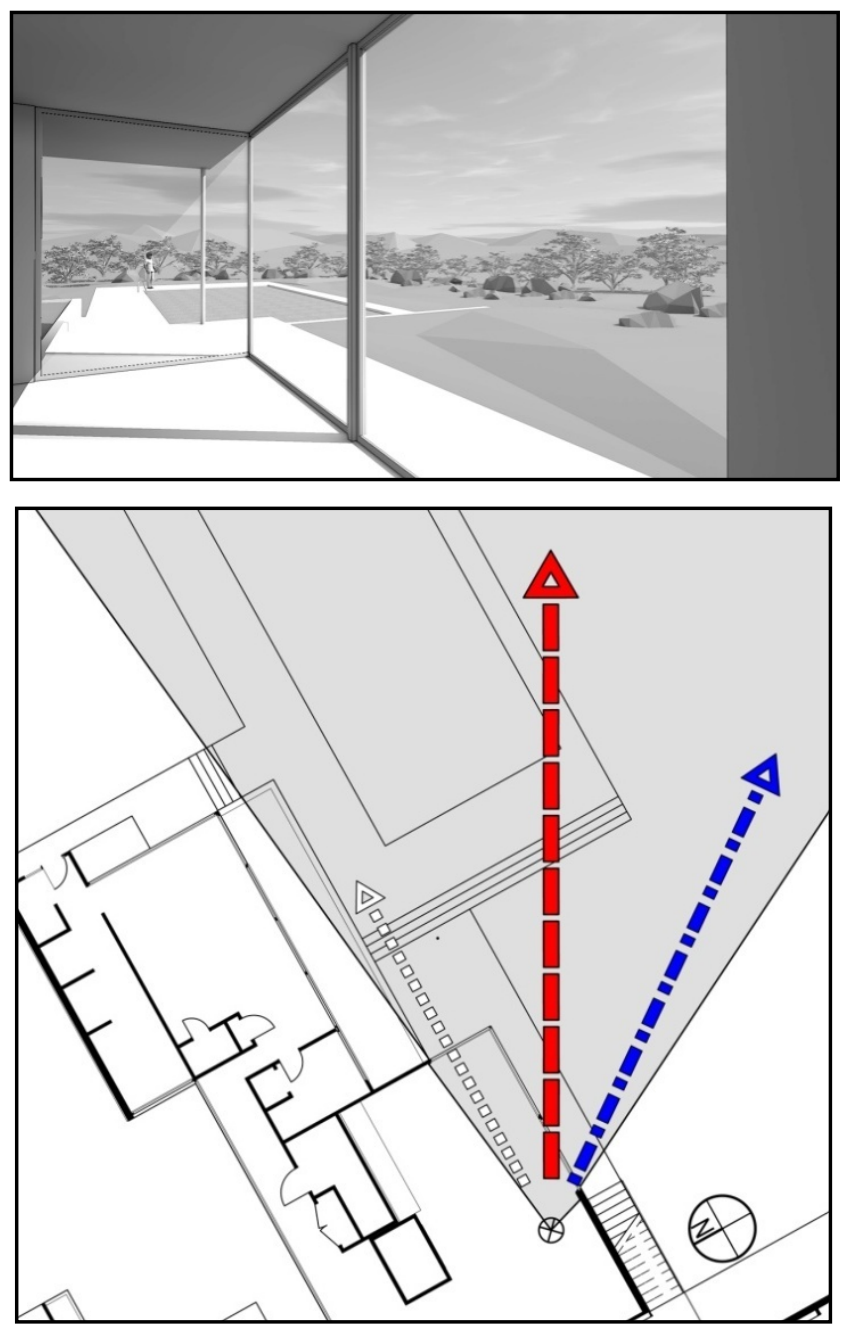

Figure 8. Parallel perspective (upper) and isovist (lower) views of the Kaufmann Desert House, annotated to identify predicted reflex response

\section{Conclusions}

The standard encyclopedia entry describes Neutra as one of "the most celebrated of the founders of modern architecture" and as a designer "who managed to capture the spirit of modernism in a powerful and memorable way"[30 p917].
Yet, throughout his life, Neutra remained committed to producing an architecture for an eternal present, a type of endless, instantaneous reflex response apparatus, where the eye (and the body as extension of the eye) responds to a safe, controlled environment; a place where fear is minimized and delight is choreographed. Neutra's architecture is not that of a physician advocating wellness -the other traditional interpretation - but of an experimental psychologist, tuning his spatial laboratory to achieve excitation control.

While past research has acknowledged Neutra psychological proclivities[14-15,20] the particular ocular-centric phenomenology that Wundt promulgated has not previously been considered in this way, nor has an attempt been made to trace evidence for this position in his architecture.

\section{ACKNOWLEDGEMENTS}

An ARC Fellowship (FT0991309) and an ARC Discovery Grant (DP1094154) supported the research undertaken in this paper. All figures by Michael Dawes and Michael Ostwald.

\section{REFERENCES}

[1] Richard J. Neutra, Mystery and Realities of the Site, Morgan \& Morgan, Scarsdale, USA, 1951.

[2] Richard J. Neutra, World and Dwelling, Universe Books, New York, USA, 1962.

[3] Richard J. Neutra, Building With Nature, Universe Books, New York, USA, 1971.

[4] Christian Norberg-Schulz, Genius Loci, Towards a Phenomenology of Architecture, Rizzoli, New York, USA, 1980.

[5] Peter MacKeith Ed., Juhani Pallasmaa: Encounters, Architectural Essays, Rakennustieto, Helsinki, 2005.

[6] Juhani Pallasmaa, The Eyes of the Skin, Architecture and the Senses, John Wiley, New York, USA, 2005.

[7] Edmund Husserl, Ideas Pertaining to a Pure Phenomenology and to a Phenomenological Philosophy-3 Volumes, F. Kersten, Trans. Nijhoff, The Hague, 1982[First Ed. 1913].

[8] Martin Heidegger, Being and Time, trans. J Macquarie \& Edward Robinson, SCM Press, London, UK , 1962[First Ed. 1927].

[9] Barbara Lamprecht, Neutra: Complete Works, Taschen, London, UK, 2000.

[10] Thomas S. Hines, Richard Neutra and the Search for Modern Architecture: a Biography and History, University of California Press, Berkeley, USA, 1982.

[11] Hanno-Walter Kruft, A History of Architectural Theory, from Vitruvius to the Present, Princeton Architectural Press, New York, USA, 1994.

[12] Esther McCoy, Richard Neutra, G. Braziller, New York, 
USA, 1960.

[13] Willy Boesiger Ed. Richard Neutra 1961-66, Buildings and Projects, Thames and Hudson, London, UK, 1966.

[14] Sylvia Lavin, "Open the Box: Richard Neutra and the Psychology of the Domestic Environment", Assemblage, vol.40, pp. 6-25, 1999.

[15] Sylvia Lavin, "Richard Neutra and the Psychology of the American Spectator", Grey Room, vol.1 (Autumn), pp. 43-63, 2000.

[16] Simon Niedenthal, "Glamourized Houses: Neutra, Photography, and the Kaufmann House", Journal of Architectural Education, vol.47, no.2, pp.101-112, 1993.

[17] Neil Leach Ed., Rethinking Architecture, a Reader in Architectural Theory, Routledge, London, UK, 1997.

[18] Daniel N. Robinson, Toward a Science of Human Nature: Essays on the Psychologies of Mill, Hegel, Wundt, and James, Columbia University Press, New York, USA, 1982.

[19] Wilhelm Wundt, Principles of Physiological Psychology, Kraus, New York, USA, 1969[First Ed. 1874].

[20] Sylvia Lavin, Form Follows Libido: Architecture and Richard Neutra in a Psychoanalytic Culture, MIT Press, Cambridge, USA, 2004.

[21] Richard J. Neutra, "Technology for Nature", William Marlin Ed., Nature Near, Late Essays of Richard Neutra, Capra Press,
Santa Barbara, USA, pp.25-32, 1989.

[22] Wilhelm Wundt, Outlines of Psychology, W. Engelmann, Leipzig, Germany, 1907.

[23] Richard J. Neutra, Life and Human Habitat, A. Koche, Stuttgart, Germany, 1956.

[24] Richard J. Neutra, Survival Through Design, Oxford University Press, Oxford, UK, 1954.

[25] Gerald J. Whitrow, The Nature of Time, Holt, Rinehart and Wilson, New York, USA, 1973.

[26] Gerald J. Whitrow, Time in History, The Evolution of Our General Awareness of Time and Temporal Perspective, Oxford University Press, Oxford, UK, 1988.

[27] Manfred Sack, Richard Neutra, Verlag für Architektur, Zürich, Switzerland, 1992.

[28] Michael J. Ostwald and Michael Dawes, "Axial Line Analysis Revisited: Reconsidering its Value for Architecture", International Journal of the Constructed Environment, vol. 1, no.3, pp.219-242, 2011.

[29] Michael Dawes and Michael J. Ostwald, "Lines of Sight, Paths of Socialization: An Axial Line Analysis of Five Domestic Designs by Richard Neutra", International Journal of the Constructed Environment, vol. 1, no. 4, pp. 1-28, 2012.

[30] R. Stephen Sennott Ed., Encyclopaedia of 20th Century Architecture: Volume 2. Fitzroy Dearborn, London, UK, 2004. 